\title{
The relationship between radiographic and clinical parameters in periodontal maintenance in class II furcation defects
}

\section{Associação entre parâmetros radiográficos e clínicos durante a terapia de manutenção periodontal em lesões de furca classe II}

\author{
Patricia Ramos Cury* \\ Ney Soares de Araújo** \\ Jon Bowie ${ }^{* * *}$ \\ Enilson Antonio Sallum**** \\ Marjorie Jeffcoat*****
}

\begin{abstract}
The goal of the present study was to investigate the relationship between probing and radiographic parameters, and the reliability of repeated longitudinal periodontal probing measurements for early diagnosis of periodontal breakdown in class II furcation defects. Eighteen class II furcation defects in lower molars were included in this study. Standardized radiographs and clinical measurements, relative vertical clinical attachment level (CAL-v) and probing depth (PD) were obtained immediately before periodontal surgeries and at $6,12,18$, and 24 months after surgery. A total of 72 pairs of radiographs were subtracted following correction for contrast and planar geometric discrepancies, and the bone loss/gain (in $\mathrm{mm}$ ) was measured. There was no statistically significant correlation between CAL-v and bone height $(\mathrm{BH})$ measurements. A statistically significant correlation for PD reduction at 24 months and $\mathrm{BH}$ increase at 18 months was found $(\mathrm{r}=0.5, \mathrm{p}<0.05)$. These results suggest that clinical measurements and radiographic bone height reflect different features of periodontal destruction and periodontal healing, and repeated longitudinal measurements of vertical clinical attachment level are not reliable for early diagnosis of periodontal breakdown in class II furcation defects.
\end{abstract}

DESCRIPTORS: Periodontitis; Bone; Radiography; Diagnosis; Furcation defects.

RESUMO: O objetivo deste estudo foi investigar a relação entre medidas clínicas e radiográficas durante a terapia de manutenção periodontal e a confiabilidade de medidas clínicas periodontais repetidas para o diagnóstico precoce de destruição periodontal de lesões de furca classe II. Dezoito lesões de furca classe II em molares inferiores foram incluídas neste estudo. Radiografias padronizadas e medidas do nível clínico de inserção vertical (NCI-v) e da profundidade de sondagem (PS) foram obtidas imediatamente antes do tratamento cirúrgico e aos $6,12,18$ e 24 meses após a cirurgia. Um total de 72 pares de radiografias foram subtraídos após correção das distorções geométricas e de contraste, e a altura de ganho/perda óssea (AO) (em mm) foi medida. Não houve correlação estatisticamente significante entre NCI-v e AO. Houve uma correlação estatisticamente significante entre redução na PS aos 24 meses e aumento na AO aos 18 meses $(r=0,5, p<0,05)$. Os resultados deste estudo sugerem que medidas clínicas e radiográficas refletem diferentes características da reparação e destruição periodontais e medidas clínicas longitudinais repetidas do NCI-v não são confiáveis para o diagnóstico precoce de destruição periodontal em lesões de furca classe II.

DESCRITORES: Periodontite; Osso; Radiografia; Diagnóstico; Defeitos da furca.

\section{INTRODUCTION}

A reliable and early diagnosis of periodontal breakdown is crucial to the decision-making during periodontal maintenance. Repeated longitudinal measurements of clinical attachment level and radiographic bone changes have been used to assess periodontal breakdown during periodontal maintenance. However, for both periodontal probing and radiographic analysis, molars present particular problems, due to their complex morphology ${ }^{3,11}$.

\footnotetext{
* Post-Doctoral Student, Department of Microbiology, Dental Research Institute, São Leopoldo-Mandic.

** Professor and Chairman, Department of Oral Pathology, School of Dentistry, University of São Paulo.

*** Doctor of Dental Medicine, Private Practice, Fairhope, USA.

$* * * *$ Professor and Chairman, Department of Periodontology, School of Dentistry, State University of Campinas.

$* * * * *$ Doctor of Dental Medicine, Department of Periodontology, School of Dental Medicine, University of Pennsylvania, Philadelphia, PA, USA.
} 
Cury PR, Araújo NS, Bowie J, Sallum EA, Jeffcoat M. The relationship between radiographic and clinical parameters in periodontal maintenance in class II furcation defects. Braz Oral Res 2004;18(2):116-20.

Clinical studies have reported mixed results on the relationship between radiographic and periodontal clinical changes in treated patients ${ }^{10,13,14}$. Zybutz et al. ${ }^{14}$ (2000) evaluated the association between clinical attachment level and radiographic measurements in 57 inter-proximal vertical defects, before and 12 months after surgical treatment ${ }^{10}$. They found almost identical results between these measurements. Machtei et al. ${ }^{10}$ (1998), studying the clinical and radiographic response to mechanical periodontal therapy, showed a positive and significant correlation between the percentage of sites with attachment level and alveolar crestal height gains; however, a weak correlation was observed for losing sites ${ }^{10}$. On the other hand, Renvert et al. ${ }^{13}$ (1981) evaluated healing after reconstructive therapy of intraosseous periodontal defects by probing attachment level, probing bone level, entry/re-entry bone height measurements, and radiographic bone height in 33 defects. Radiographic bone height showed low degrees of correlation with all three probing parameters ${ }^{13}$. To our knowledge, no information is available on association between changes of clinical attachment level and bone height in class II furcation defects.

The aim of the present study was to investigate: 1 - the association between changes of clinical parameters and bone height in class II furcation defects; 2- the reliability of repeated longitudinal measurements of vertical clinical attachment level for early diagnosis of periodontal breakdown in class II furcation defects, considering digital subtraction radiography as the "gold standard".

\section{MATERIAL AND METHODS}

The study protocol was approved by the State University of Campinas Institutional Committee of Ethics. Informed consent was obtained from all subjects. A total of 18 class II furcation defects in lower molars of 9 systemically healthy patients diagnosed with chronic periodontitis were selected for this study. The defects were treated by either guided tissue regeneration or open flap debridement and enrolled in a maintenance program as described previously ${ }^{1}$. Briefly, the surgeries consisted of intrasulcular incisions, mucoperiosteal flaps, and the removal of granulation tissue. The root surfaces were thoroughly scaled and planed. The area was rinsed with sterile saline (Proderma, Piracicaba, Brazil) and a 10\% tetracycline solution (Proderma, Piracicaba, Brazil) was applied to the root surface for 3 minutes. In nine defects, bio- absorbable polylactic acid membranes (Guidor ${ }^{\circledR}$ bioresorbable matrix barrier, Guidor AB, Novum, Huddinge, Sweden) were fitted to cover the furcation and 3 to $4 \mathrm{~mm}$ of alveolar bone beyond the defect. The flaps were coronally displaced and secured with interdental expanded polytetrafluoroethylene sutures. Patients were seen every 2 weeks for 6 months for professional prophylaxis and reinforcement of oral hygiene procedures and every 3 months thereafter for 18 months for periodontal maintenance.

The clinical measurements were obtained by one calibrated examiner, using a University of North Carolina periodontal probe. The examiner was not aware of the treatment distribution or radiographic results. For relative vertical clinical attachment level and relative gingival recession measurements, a prefabricated stent (Proderma, Piracicaba, Brazil) was used to reproduce probing site and angulation, and an endodontic rubber stopper was adapted to the probe and slid to the margin of the stent. The measurements were obtained using the probe scale and checked with a caliper (Vernier Caliper, Mitutoyo Corporation, Kanagawa, Japan). The parameters were recorded at the center of the furcation site. The probing depth (PD) was determined by computing the difference between CAL- $v$ and gingival recession (GR).

Before the study and every 6 months, the examiner performed 3 repeated probing examinations in 10 class II furcation defects in 5 patients. The differences among the examinations were within $1 \mathrm{~mm}$ in $91.6 \%$ of the measurements for relative gingival recession (GR) and vertical clinical attachment level (CAL-v), which was not statistically significant $(\mathrm{p}>0.09)$.

The clinical parameters and standardized vertical bitewing radiographs (Kodak Ectaspeed dental films, Eastman Kodak Company, Rochester, USA) were obtained at baseline (immediately before surgery) and at 6, 12, 18, and 24 months postoperatively.

The radiographs were taken with the longcone paralleling technique employing an X-ray unit (General Electric, New York, USA) operating at $70 \mathrm{kV}, 10 \mathrm{~mA}$, and 0.8 seconds exposure time. In order to standardize the geometry, a commercial system (XCP, Rinn Corporation, Elgin, USA) was used. It was modified and connected to an individual acrylic bite-block with occlusal registration of autopolymerizing acrylic resin. The film was 
Cury PR, Araújo NS, Bowie J, Sallum EA, Jeffcoat M. The relationship between radiographic and clinical parameters in periodontal maintenance in class II furcation defects. Braz Oral Res 2004;18(2):116-20.

processed by an automatic film processor (GXP, Gendex, New York, USA) ${ }^{1}$.

For each site the baseline radiograph was placed under a video camera, digitized and stored in the computer. The follow-up radiographs were aligned under the video camera and digitized. Pairs of radiographs were subtracted following correction for contrast and planar geometric discrepancies as previously described ${ }^{8}$. The resultant subtraction image showed areas of bone loss (dark areas) and bone gain (light areas) against a neutral gray background. In order to measure the change in bone height, the computer software measured the length of the region of bone loss or gain (in $\mathrm{mm}$ ) that intersected with the tooth root $^{1}$. All radiographic measurements were performed by one examiner blinded to clinical results.

\section{Statistical analysis}

The relationship between probing and bone height measurements was analyzed by simple linear regression. The coefficients of correlations between the clinical and radiographic parameters were similar for defects treated by guided tissue regeneration and open flap debridement, thus, these defects were pooled for the purpose of presentation of this study.

\section{RESULTS}

All the patients completed the 24-month follow-up and all the clinical and radiographic measurements and were included in this report.

Graph 1 shows the changes in relative vertical clinical attachment level (CAL-v), probing depth (PD), and bone level (BL). There was no statistically significant correlation between vertical clinical attachment level and bone level gain at any exam $(p>0.05)$. A statistically significant correlation for probing depth reduction at 24 months and bone height increase at 18 months was found $(r=0.5$, $\mathrm{p}<0.05)$.

There was no statistically significant correlation between clinical attachment level and bone height at any examination. CAL-v versus bone height gains were: $0.89 \pm 1.21 \mathrm{~mm}$ versus $0.34 \pm 1.18 \mathrm{~mm}$ at 6 months; $1.08 \pm 1.96 \mathrm{~mm}$ versus $0.58 \pm 0.72 \mathrm{~mm}$ at 12 months; $0.95 \pm 1.60 \mathrm{~mm}$ versus $0.94 \pm 1.27 \mathrm{~mm}$ at 18 months; and $0.43 \pm 1.89 \mathrm{~mm}$ versus $1.03 \pm 1.29 \mathrm{~mm}$ at 24 months $(\mathrm{r}<0.29, \mathrm{p}>0.26)$.

A statistically significant correlation only for probing depth reduction at 24 months

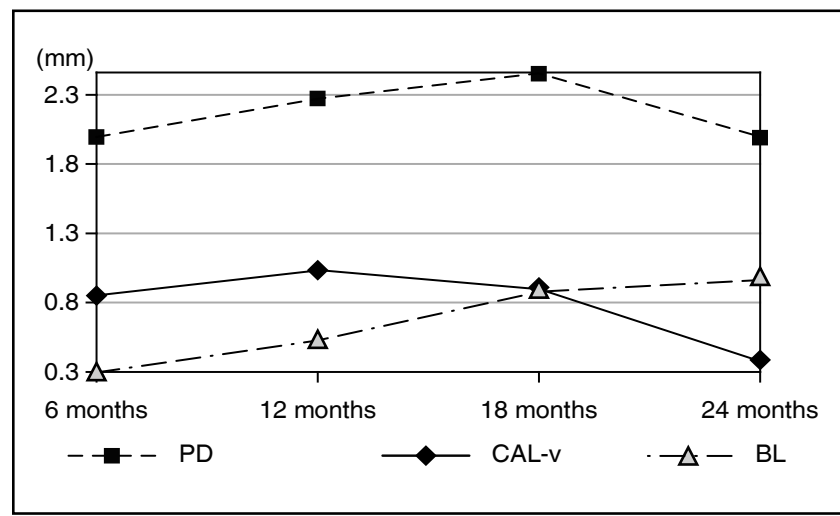

GRAPH 1 - Changes in relative vertical clinical attachment level (CAL-v), probing depth (PD), and bone level (BL). There was no statistically significant correlation between vertical clinical attachment level and bone level gain at any exam $(\mathrm{p}>0.05)$. A statistically significant correlation for probing depth reduction at 24 months and bone height increase at 18 months was found $(\mathrm{r}=0.5, \mathrm{p}<0.05)$.

and bone height increase at 18 months was found $(\mathrm{r}=0.5, \mathrm{p}=0.05)$. $\mathrm{PD}$ reductions were $2.03 \pm 1.49 \mathrm{~mm}, 2.31 \pm 1.94 \mathrm{~mm}, 2.49 \pm 1.76 \mathrm{~mm}$, and $2.23 \pm 1.87 \mathrm{~mm}$, at $6,12,18$, and 24 months, respectively.

\section{DISCUSSION}

In the present study, several factors may have contributed to the weak correlation between clinical and radiographic measurements: (a) changes in the vertical clinical attachment level and probing depth might be the result of resolution of the inflammation and new attachment without any bone change ${ }^{4}$; (b) low sensitivity of manual probing, since probing has been associated with great variability and digital subtraction radiography is highly sensitive and specific for detection of small osseous changes ${ }^{8}$. Perhaps, a higher degree of correlation would have been found using an electronic probe, as observed by Jeffcoat ${ }^{7}$ (1992), Hausmann et al. ${ }^{6}$ (1994) and Machtei et al..$^{9}$ (1997). However, similar to other studies ${ }^{2,5,10,13,14}$, in the present research, a manual probe was used. Pilgram et al. ${ }^{12}$ (1999) employed a pressure-sensitive probe and also observed a weak correlation between attachment level and radiographic bone height $(\mathrm{r}=0.45$; $\mathrm{p}>0.05)^{12}$.

Considering non-treated patients, Jeffcoat ${ }^{7}$ (1992) and Hausmann et al. ${ }^{6}$ (1994) showed 82\% of concordance between clinical attachment level and bone loss in patients with periodontal pock- 
Cury PR, Araújo NS, Bowie J, Sallum EA, Jeffcoat M. The relationship between radiographic and clinical parameters in periodontal maintenance in class II furcation defects. Braz Oral Res 2004;18(2):116-20.

ets $^{6,7}$, and Machtei et al. ${ }^{9}$ (1997) found that over a short period of time, clinical attachment level and radiographic bone level might not follow the same course; however, in the long term, the differences seem to level off ${ }^{9}$, in disagreement with the present study. However, in the present study, the insignificant correlation between clinical measurements and bone height is in agreement with one study $^{12}$. It is interesting to note that Hausmann et al. ${ }^{6}$ (1994) reported a direct and significant relationship between bone and probing attachment loss ( $\mathrm{p}<0.0014)$, however, it is possible to observe in their table that the concordance between bone loss and probing attachment loss was very low (less than $2.6 \%$ ), which is similar to our results. The reported $82 \%$ of concordance between radiographic and attachment level measurements have been found due to the high concordance between bone and probing attachment only in non-changing sites.

Considering treated sites, Machtei et al. ${ }^{10}$ (1998) found a positive and significant correlation between the percentage of sites with attachment level and alveolar crestal height gain; however, the overall correlation between clinical and radiographic changes following therapy was weak ${ }^{10}$. In inter-proximal vertical defects, Zybutz et al. ${ }^{14}$ (2000) found almost identical results regarding the correlation between clinical attachment level and radiographic measurements. Conversely, Renvert et al. ${ }^{13}(1981)$ observed a weak correlation $(\mathrm{r}=0.45$; $\mathrm{p}>0.05)$. The results of the present study are in

\section{REFERENCES}

1. Cury PR, Sallum EA, Nociti FH Jr, Sallum AW, Jeffcoatt MK. Long-term results of guided tissue regeneration therapy in the treatment of class II furcation defects: a randomized clinical trial. J Periodontol 2003;74:3-9.

2. Eickholz P, Hausmann E. Evidence for healing of interproximal intrabony defects after conventional and regenerative therapy: digital radiography and clinical measurements. J Periodontal Res 1998;33:156-65.

3. Eickholz P, Kim TS. Reproducibility and validity of the assessment of clinical furcation parameters as related to different probes. J Periodontol 1998;69:328-36.

4. Gargiulo AW, Wentz FM, Orban B. Dimensions and relations of the dentogingival junctions in humans. J Periodontol 1961;32:261-9.

5. Goodson JM, Haffajee AD, Socransky SS. The relationship between attachment level loss and alveolar bone loss. J Clin Periodontol 1984;11:348-59.

6. Hausmann E, Allen K, Norderyd J, Ren W, Shibly O, Machtei E. Studies on the relationship between changes in radiographic bone height and probing attachment. J Clin Periodontol 1994;21:128-32. agreement with most of the studies ${ }^{10,13}$. In contrast to all previous studies in literature, only class II furcations were included. Thus, the sampled sites were more homogeneous, although taking clinical and radiographic evaluations was more difficult.

It was shown that periodontal attachment loss precedes radiographic evidence of crestal alveolar bone loss by 7 to 16 months, during periodontal disease activity ${ }^{11}$. However, in this study, there was a statistically significant correlation for probing depth reduction at 24 months and bone height increase at 18 months $(\mathrm{r}=0.5)$, but no temporal relationship between attachment and bone changes was found.

\section{CONCLUSION}

Within the limits of the present study, it can be concluded that:

- clinical measurements and radiographic bone height reflect different features of periodontal destruction and periodontal healing;

- repeated longitudinal measurements of vertical clinical attachment level might not be reliable for early diagnosis of periodontal breakdown in class II furcation defects.

\section{ACKNOWLEGDEMENTS}

This project was supported by FAPESP (The State of São Paulo Research Foundation, grant 99/03544-2).

7. Jeffcoat MK. Radiographic methods for the detection of progressive alveolar bone loss. J Periodontol 1992;63:36772 .

8. Jeffcoat MK, Reddy MS, Magnusson I, Johnson B, Meredith MP, Cavanaugh PF Jr, et al. Efficacy of quantitative digital subtraction radiography using radiographs exposed in a multicenter trial. J Periodontal Res 1996;31:157-60.

9. Machtei EE, Hausmann E, Grossi SG, Dunford R, Genco RJ. The relationship between radiographic and clinical changes in the periodontium. J Periodontal Res 1997;32:661-6.

10. Machtei EE, Hausmann E, Schmidt M, Grossi SG, Dunford R, Schifferle R, et al. Radiographic and clinical responses to periodontal therapy. J Periodontol 1998;69:5905 .

11. Moriarty JD, Scheitler LE, Hutchens LH Jr, Delong ER. Inter-examiner reproducibility of probing pocket depths in molar furcation sites. J Clin Periodontol 1988;15:6872 .

12. Pilgram TK, Hildebolt CF, Yokoyama-Crothers N, Dotson M, Cohen SC, Hauser JF, et al. Relationships between longitudinal changes in radiographic alveolar bone height 
Cury PR, Araújo NS, Bowie J, Sallum EA, Jeffcoat M. The relationship between radiographic and clinical parameters in periodontal maintenance in class II furcation defects. Braz Oral Res 2004;18(2):116-20.

and probing depth measurements: data from postmenopausal women. J Periodontol 1999;70:829-33.

13. Renvert S, Badersten A, Nilveus R, Egelberg J. Healing after treatment of periodontal intraosseous defects. I. Comparative study of clinical methods. J Clin Periodontol $1981 ; 8: 387-99$.
14. Zybutz M, Rapoport D, Laurell L, Persson GR. Comparisons of clinical and radiographic measurements of inter-proximal vertical defects before and 1 year after surgical treatments. J Clin Periodontol 2000;27:179-86.

Received for publication on Sep 08, 2003 Accepted for publication on Apr 19, 2004 